\title{
PENSAR A ESCOLA PÚBLICA EM TEMPOS DE MICRO RESISTENCIAS
}

\author{
THINK PUBLIC SCHOOL IN TIMES OF MICRO RESISTANCES \\ PENSAR LA ESCUELA PÚBLICA EN TIEMPOS DE MICRO RESISTENCIAS
}

\author{
Gilberto Oliari* \\ gilba@unochapeco.edu.br \\ Elisete Medianeira Tomazetti** \\ elisetem2@gmail.com \\ Jéssica Erd Ribas*** \\ erd.jessica@gmail.com \\ Raquel Brum Sturza**** \\ raquelsturza@hotmail.com
}

\begin{abstract}
REVISTA PEDAGÓGICA
Revista do Programa de Pós-graduação em Educação da Unochapecó | ISSN 1984-1566

Universidade Comunitária da Região de Chapecó | Chapecó-SC, Brasil

Como referenciar este artigo: OLIARI, G.; TOMAZETTI, E. M.; RIBAS, J. E.; STURZA, R. B. Pensar a escola pública em tempos de micro resistências. Revista Pedagógica, Chapecó, v. 19, n. 42, p. 183-186, set./dez. DOI: http://dx.doi.org/10.22196/rp.v19i42.3984
\end{abstract}

Resenha do livro: MASSCHELEIN, Jan; SIMONS, Maarten. Em defesa da escola: uma questão pública. 2. ed. Belo Horizonte: Autêntica, 2017.

O livro Em defesa da Escola, de Jan Masschelein e Maarten Simons, quando lido no contexto brasileiro, onde há forte interferência de instituições e de órgãos não governamentais sobre a educação básica, pode ser considerado, em seu corpus argumentativo, uma resistência ao desmonte e a descaracterização do ensino público do país. Os autores problematizam os argumentos de que a escola deve direcionar os alunos para uma profissionalização. É uma obra de relevância, pois ancora suas reflexões nos escritos de Hannah Arendt, escritora amplamente difundida no Brasil, e, acompanhado de outros autores/pensadores defende que a escola deve ser um espaço de tempo livre, skholé, para a criação, para a natalidade juvenil e para a mudança do mundo comum.

Leitura indispensável para professores da educação básica e para estudantes de pós-graduação em educação, pois o texto contribui para pensar a escola em seus microprocessos de resistência e de formação. Ao defender a escola como uma questão pública, defende também o professor, o qual apesar de todos os ataques recebidos, busca exercer a responsabilidade de preservar o mundo, ou seja, preservar que o aspecto criador dos jovens. Outra tese apresentada e, talvez a mais importante, é a de que a escola é um espaço onde se cria igualdade social, que sustenta o sonho do progresso social e de emancipação. Por isso, o papel do professor é importante, pois esse profissional pode ser entendido como o agente capaz 


\footnotetext{
* Doutorando em Educação. Programa do Programa de Pós-Graduação em Educação - UFSM. Professor de Educação Básica Santa Catarina.

** Doutora em educação. Professora Titular do Departamento de Metodologia do ensino. Curso de Filosofia. Centro de educação. Professora do Programa de Pós-Graduação em Educação - UFSM.

*** Mestranda em Educação. Programa do Programa de Pós-Graduação em Educação - UFSM.

**** Mestranda em Educação. Programa do Programa de Pós-Graduação em Educação - UFSM.
}

“[...] de ajudar os alunos escaparem de seu mundo da vida e de seu (aparentemente predestinado) lugar e posição na ordem social" (p. 68).

A presente obra foi escrita por dois professores que coordenam o Laboratório para Educação e Sociedade da Universidade de Louvain, Bélgica. A tese central defendida é que a escola, desde sua origem na Grécia Antiga, tem como função oferecer tempo livre para as novas gerações que chegam ao mundo e, é imprescindível que se retome essa sua "essência", já que oferecer tempo livre aos estudantes significa possibilitar o exercício de pensamento sobre o conteúdo das disciplinas, mas também sobre os valores sociais, sobre o mundo e sobre si mesmo. Essa obra se constrói com vistas a rebater um conjunto de críticas feitas à escola. E, é pela retomada dessas críticas que a obra inicia.

No primeiro capítulo, intitulado Acusações, demandas, posições, os autores remontam cinco argumentos utilizados por diferentes sistemas políticos e educacionais para afirmar que a escola precisa ser reformada. Pode-se afirmar que há uma afirmação, ainda na introdução da obra, que move toda a construção argumentativa: "nós aprendemos muito mais e muito melhor fora da escola" (p. 10), em nome disso as críticas se tecem apontando que a escola aliena os jovens, consolida poderes, desmotiva a juventude, não possibilita empregabilidade e, por isso, é demandada sua reforma. Masschelein e Simons rebatem esses argumentos apontando que existe um ódio contra a característica mais radical da escola, qual seja, oferecer "tempo livre" a todos que nela estão (p. 27). E se pensarmos de forma madura, o que se pode perceber é que, de fato, algumas instâncias sociais quase criminalizam a escola por discutir temas filosoficamente e socialmente relevantes e, defendem que a escola deve se preocupar com a profissionalização dos estudantes, como se pensar e posicionar-se criticamente não fizesse parte do processo formativo da escola.

O segundo capítulo - O que é escolar - inicia afirmando que "[...] a escola é, igualmente, o lugar onde os jovens (de acordo com um método específico) são abastecidos com tudo o que eles devem aprender para encontrar o seu lugar na sociedade" (p. 25). Para que haja esse abastecimento, é necessário que os jovens - saindo do ninho familiar e adentrando na escola - façam um processo de suspensão (afastamento) das necessidades e rotinas cotidianas de vida, para que possam analisá-las, inserir-se em outros mundos possíveis (conhecimentos) e, a partir daí, pensar sobre o seu papel na transformação do mundo comum. Muito embora saibamos que existem muitos ataques à educação escolar, defende-se que a escola deve ser um local entre margens. A escola não está ancorada em lugar nenhum, pois tem como tarefa "suspender" o mundo para estudá-lo, tem na formação o seu processo e o seu fim. O professor deve ser aquele que ama sua matéria, que se preocupa com seus temas e, por esse motivo, tem voz ativa nesse processo, pois cabe a ele a responsabilidade de apre- 
sentar o mundo como ele é para as diferentes gerações e possibilitar que pensem sua inserção no mundo comum. O professor, que personifica sua matéria, chama atenção dos estudantes, desperta neles interesse, os envolve e os inspira na aula, a tal ponto que o que é externo acaba por ficar em segundo plano.

A construção textual argumentativa dos autores baseia-se nos escritos arendtianos sobre educação. Nesse sentido, o terceiro capítulo da obra, vai apresentar a tessitura de uma crítica às tentativas e, muitas vezes vitórias, das políticas públicas "domarem" a escola. Esse é o tema do terceiro capítulo que tem como título Domando a escola. Para os autores "domar a escola implica governar seu caráter democrático, público e renovador” (p. 105). Esse processo não torna os alunos sujeitos de seu processo de formação e de vida, porque, muitas vezes, estes se tornam meros "consumidores" de conteúdos, não ressignificam e não buscam integrar-se nesse mundo comum. As tentativas de domar se referem à: politização - responsabilização pela transformação dos problemas sociais existentes; pedagogização - posicionamento paternal/maternal dos professores, como se estes fossem babás de meio período (ou integral); naturalização - dos processos de seleção aristocrática e meritocrática dos estudantes; tecnologização - técnicas que visam a uma maior eficácia para cumprir metas estabelecidas e performatividade dos resultados e ganhos da aprendizagem; psicologização - substituição do ensino por uma forma de orientação psicológica; popularização - utilização de técnicas do mundo do entretenimento nas salas de aula para fugir do "tédio".

No quarto capítulo da obra - Domando o professor encontra-se uma série de argumentos voltados ao processo de retirada da autonomia docente. Esse processo, de domesticar o professor, acontece justamente por que sua atividade é uma atividade que não acontece em uma empresa nem mesmo em uma oficina. É uma atividade que não se filia a nenhuma ordem social e, portanto, é uma figura pública que desestabiliza ou "torna suspensa" a ordem estabelecida. A busca por domá-los "consistia e consiste em neutralizar ou "profissionalizar" a dupla relação de amor ou em transformá-la em uma relação de obediência” (p. 136), ou seja, transforma os professores em "funcionários civis" que respondem às ordens. Nesse sentido, a profissionalização acontece por meio da especialização, do ensino, como profissão atenta às exigências de mercado e de consumo, da pressão por responsabilidade, que se dirige ao processo de qualificação do processo educativo. Essa pressão exercida transforma-se na exigência mercadológica de flexibilização e mobilidade, as quais o docente precisa estar atento para poder "encaixar-se", no treino e nos padrões, dos novos modelos educacionais, sem perder a direção da qualidade e da profissionalidade.

O quinto e último capítulo, intitulado Experimentum scholae: a igualdade do começo, apresenta uma síntese 
das ideias apresentadas até o momento e defende que as tentativas de domar a escola estão imbricadas de um desejo de domar a própria dimensão democrática e comunista da sociedade (comunismo aqui entendido como dar tempo igual, comum, a todos que entram para a escola) e, por isso "a escola rejeita toda e qualquer noção de um destino predeterminado" (p. 157), uma vez que não se trata de destino, mas de oportunidade de desenvolver capacidades. Trata-se de afirmar que "[...] todos os estudantes são capazes. Por isso, a grande defesa, que deve ser comum, de que a escola tem a intenção de puxar os jovens para fora de seus próprios mundos para que eles possam começar a formar a si mesmos" (p. 170) e, assim, garantir a renovação do mundo comum.

A obra apresenta um princípio conceitual que possibilita a reflexão teórica e prática da escola; nas palavras dos autores "é uma hipótese prática - não é uma certeza científica” (p. 71). Desse modo, é válido ler o livro em seu conjunto de conceitos e perceber a necessidade de tensionar e problematizar visões. Portanto, é uma obra que demanda um debruçar-se com "tempo livre" para a leitura, para evitar interpretações distorcidas e equivocadas das ideias dos autores. Por fim, a leitura pode dar um aparato teórico conceitual para aqueles que defendem a escola nos dias de hoje.

Recebido em: 26/09/2017 Aprovado em: 31/10/2017 